\title{
Membrane Mineralocorticoid but not Glucocorticoid Receptors of the Dorsal Hippocampus Mediate the Rapid Effects of Corticosterone on Memory Retrieval
}

\author{
Rodolphe Dorey ${ }^{1,2,5}$, Christophe Piérard ${ }^{2,5}$, Svitlana Shinkaruk ${ }^{3,4}$, Christophe Tronche ${ }^{1,2}$, \\ Frédéric Chauveau' ${ }^{2}$, Mathieu Baudonnat' and Daniel Béracochéa*,I \\ 'CNRS, Institut de Neurosciences Cognitives et Intégratives d'Aquitaine (INCIA) UMR 5287, Universités de Bordeaux, Talence, France; \\ ${ }^{2}$ Institut de Recherche Biomédicale des Armées (IRBA)—Unité Fatigue et Vigilance, Brétigny sur Orge, France; ${ }^{3}$ U862 Inserm Physiopathologie \\ de la plasticité neuronale, Institut François Magendie, Universités de Bordeaux, Bordeaux, France; ${ }^{4}$ ENITA de Bordeaux, Gradignan, France
}

\begin{abstract}
This study was aimed at determining the type of the glucocorticoid membrane receptors (mineralocorticoid receptors (MRs) or glucocorticoid receptors (GRs)) in the dorsal hippocampus (dHPC) involved in the rapid effects of corticosterone or stress on memory retrieval. For that purpose, we synthesized corticosterone-3-O-carboxymethyloxime-bovine serum albumin conjugate (Cort-3CMOBSA) conjugate (a high MW complex that cannot cross the cell membrane) totally devoid of free corticosterone, stable in physiological conditions. In a first experiment, we evidenced that an acute stress (electric footshocks) induced both a dHPC corticosterone rise measured by microdialysis and memory retrieval impairment on delayed alternation task. Both the endocrinal and cognitive effects of stress were blocked by metyrapone (a corticosterone synthesis inhibitor). In a second experiment, we showed that bilateral injections of either corticosterone or Cort-3CMO-BSA in dHPC 15 min before memory testing produced impairments similar to those resulting from acute stress. Furthermore, we showed that anisomycin (a protein synthesis inhibitor) failed to block the deleterious effect of Cort3CMO-BSA on memory. In a third experiment, we evidenced that intra-hippocampal injection of RU-283I8 (MR antagonist) but not of RU-38486 (GR antagonist) totally blocked the Cort-3CMO-BSA-induced memory retrieval deficit. In a fourth experiment, we demonstrated that RU-28318 administered 15 min before stress blocked the stress-induced memory impairments when behavioral testing occurred $15 \mathrm{~min}$ but not $60 \mathrm{~min}$ after stress. Overall, this study provides strong in vivo evidence that the dHPC membrane GRs, mediating the rapid and non-genomic effects of acute stress on memory retrieval, are of MR but not GR type.

Neuropsychopharmacology (20II) 36, 2639-2649; doi:I0.I038/npp.20I I.I52; published online 3 August 20I I
\end{abstract}

Keywords: membrane glucocorticoid receptors; hippocampus; corticosterone; Cort-BSA; stress; memory retrieval

\section{INTRODUCTION}

The effects of glucocorticoids (GCs) on memory processes have been attributed to classic steroid mechanisms involving delayed transcriptional regulation (McEwen and Sapolsky, 1995; de Kloet et al, 1999; Sapolsky et al, 2000; Lupien and Lepage, 2001; McGaugh and Roozendaal, 2002; Donley et al, 2005; Joels et al, 2006). From a functional point of view, the molecular mechanisms mediating the effects of GCs on memory formation are largely unknown. However, AMPA receptor expression and trafficking have been implicated (Groc et al, 2008; Conboy and Sandi, 2010). In addition, recent findings in neuroendocrinology suggest

*Correspondence: Dr D Beracochea, CNRS, Institut de Neurosciences Cognitives et Integratives d'Aquitaine (INCIA) UMR 5287, Universités de Bordeaux, Talence 33400, France, Tel: + 3354000 2439, Fax: + 33 54000 8743, E-mail: d.beracochea@cnic.u-bordeauxl.fr

${ }^{5}$ These two authors contributed equally to this work.

Received 24 March 20 I ; revised 5 July 201 I; accepted 5 July 20I I that steroids can rapidly modulate neuronal activity (within a few minutes) through a non-genomic pathway via an activation of membrane receptors (Borski, 2000; Falkenstein et al, 2000; Makara and Haller, 2001; Dallman, 2005; Tasker et al, 2006). It has also been shown that GCs increase the release of excitatory amino acids (Venero and Borrell, 1999), reduce unit discharge of hippocampal neuron in rat hippocampus via a rapid non-genomic action (Pfaff $e t$ al, 1971), and modulate neuronal activity and synaptic excitatory transmission (Chaouloff and Groc, 2011).

However, rapid effects of corticosterone on behavior and cognitive processes are seldom documented (Sajadi et al, 2006; Orchinik et al, 1991; Sandi et al, 1996; Breuner et al, 1998). Previous studies from our team provided first clearcut evidence in behaving animals of the involvement of dorsal hippocampal membrane receptors in the mediation of the rapid deleterious effects of stress on memory retrieval. More specifically, we showed that bilateral infusion into the dorsal hippocampus (dHPC) of corticosterone-bovine serum albumin conjugate (Cort-BSA), a high 
MW complex that cannot cross the cell membrane, produced deleterious effects on memory retrieval similar to those resulting from an acute stress administration delivered $5 \mathrm{~min}$ before memory testing (Chauveau et al, 2010).

Our previous study did not determine, however, the type of membrane GC receptors (GRs) involved in the rapid effects of Cort-BSA nor that of acute stress on memory retrieval. To our knowledge, only in vitro or electrophysiological studies have as yet demonstrated that the rapid effects of corticosterone or stress may be mediated through mineralocorticoid receptors (MRs) activity. Thus, it has been shown that MRs but not GRs are required for nongenomic modulation of hippocampal glutamate transmission by corticosterone (Karst et al, 2005). In contrast, in behaving animals, a recent study evidenced that Cort-BSA administered in the medial prefrontal cortex $1 \mathrm{~h}$ before memory testing enhances memory consolidation, but impaired working memory, and that these Cort-BSAinduced impairments were blocked by co-administration of a GR but not an MR antagonist (Barsegyan et al, 2010). So far, the issue of the type of the membrane-bound steroid receptor involved in the rapid effects of GCs on cognitive processes remains seldom documented in behaving animals, and more particularly as regards the type of hippocampal membrane GRs involved in the rapid effects of corticosterone or stress on memory retrieval. Indeed, several studies have already evidenced the involvement of both types of hippocampus GRs in memory retrieval, but these experiments were not designed to evidence the involvement of $\mathrm{MR}$ or GR at the membrane level (Roozendaal et al, 2004; Khaksari et al, 2007; Ferguson and Sapolsky, 2007).

Accordingly, as Cort-BSA directly acts on membrane receptors and induced memory retrieval impairments (Chauveau et al, 2010), we intended in the study hereby to determine the ability of selective antagonists of the MRs or GRs to block the rapid effects of either acute stress or intra-hippocampus Cort-BSA infusions on memory retrieval. Hence, we synthesized, characterized, and purified a new Cort-BSA complex, that is, Cort-3CMO-BSA (Cort-3$O$-carboxymethyloxime-BSA conjugate) totally devoid of free corticosterone that could trigger non-membrane effects. The Cort-3CMO-BSA complex that we developed offers the advantage, as compared to commercial products, of having a higher corticosterone density on carrier BSA.

From a behavioral standpoint, to avoid the use of reinforcements that may interfere either with stress or with the pharmacological treatments, we evaluated memory retrieval processes using non-rewarded alternation behavior, in which the delayed alternation rate is an index of memory performance (Beracochea and Jaffard, 1985; Borde et al, 1996; Chauveau et al, 2005).

\section{MATERIALS AND METHODS}

\section{Experimental Design}

Experiment 1 tested the impact of an acute stress delivered 15 min before the test session of the delayed alternation task. In parallel, the time course of the stress-induced corticosterone rise in the dorsal intra-hippocampus was measured in independent groups of mice. Moreover, to evidence the causal role of the stress-induced hippocampal corticosterone rise on memory retrieval dysfunction, we also evaluated the effects of an intraperitoneal pre-test metyrapone administration (a corticosterone synthesis inhibitor) on both the behavioral and endocrinal measures.

In Experiment 2, corticosterone or Cort-3CMO-BSA was bilaterally administered into the dHPC $15 \mathrm{~min}$ before the test session, to determine if these compounds produced memory retrieval deficits similar to those resulting from stress, and the involvement of membrane GRs' activation in the mediation of the rapid deleterious effects of corticosterone on memory retrieval. Moreover, to ensure that the rapid effects of Cort-3CMO-BSA are not mediated by genomic pathway, we administered in independent groups of mice anisomycin (an inhibitor of protein synthesis) $45 \mathrm{~min}$ before the infusion of Cort-3CMO-BSA.

In Experiment 3, the GR antagonist RU-38486 (mifepristone) or the MR antagonist RU-28318 was injected into the dHPC 15 min before the injection of Cort-3CMO-BSA. The blockade of either MRs or GRs by selective antagonists should block the effects of intra-hippocampus Cort-3CMOBSA injection on memory performance, and accordingly will allow determination of the type (MRs or GRs) of the membrane GRs mediating the effects of Cort-3CMO-BSA on memory retrieval.

In Experiment 4, given the results obtained in Experiment 3 , the MR antagonist RU-28318 was bilaterally injected into the dHPC 15 min before acute stress delivery; the test session occurred, however, either 15 or $60 \mathrm{~min}$ after stress delivery. This experiment allowed us to determine if RU-28318 will block the effects of stress on memory retrieval similarly as for Cort-3CMO-BSA (Experiment 3) and the time course for such an effect.

\section{Animals}

The subjects were 6-month-old naive male mice of the C57BL/6 inbred strain obtained from Charles Rivers (L'Arbresle, France). At the time of the experiments, mice weighed between 28 and $32 \mathrm{~g}$. They were housed individually with free access to water on a $12 \mathrm{~h}$ light-dark cycle in a temperature-controlled and ventilated room. Tests were conducted during the light phase of the cycle between 0800 and 1200 hours. The number of animals used in each group is given in the Result section.

\section{Surgery and Histology}

Mice were anesthetized with a ketamine $(1 \mathrm{mg} / \mathrm{kg}$ body weight)-xylazine (10 mg/kg body weight) solution and placed on a stereotaxic frame. All stereotaxic coordinates are referenced in $\mu \mathrm{m}$ from the bregma (Paxinos and Franklin, 2001). For pharmacological administration, two stainless-steel guide cannulae (26 G, $8 \mathrm{~mm}$ length) were implanted bilaterally $1 \mathrm{~mm}$ above the surface of the dHPC $(\mathrm{AP}=-2000 ; L= \pm 1400 ; V=-1000)$. Guide cannulae were fixed in place with dental cement and two microscrews attached to the skull. All operated mice were allowed to recover in their home cages in the animal room for at least 7 days before the behavioral experiments began. After completing the behavioral test, all mice were killed to collect 
brains. All the brains were coronally sectioned $(50 \mu \mathrm{m}$ thickness). A cresyl violet stain was used to verify the exact probe location in dorsal HPC.

\section{Pharmacological Administration}

In Experiment 1, all subjects were habituated for prick effect in the animal room without perforating the skin during 5 consecutive days. On the day of experiment and $30 \mathrm{~min}$ before the acute stress delivery, mice received an intraperitoneal injection of metyrapone (Promochem; $35 \mathrm{mg} / \mathrm{kg}$ body weight dissolved in a solution of $5 \%$ ethanol in saline) in a room different from that used for behavioral testing.

In Experiment 2, a 32-G stainless-steel cannula (9 mm length) attached to a microsyringe with polyethylene catheter tubing was inserted into the guide cannula. The syringes were placed in a constant flow rate pump $(0.4 \mu \mathrm{l} / \mathrm{min})$. Corticosterone (Sigma, France) or Cort3CMO-BSA was diluted in mock CSF (vehicle) at the concentration of $1 \mathrm{mg} / \mathrm{ml}$, and bilaterally injected ( $1 \mu \mathrm{l}$ per side) into the dHPC. The cannulae were left in place for $3 \mathrm{~min}$ before removal to allow the diffusion of the drugs from the cannulae tips. Corticosterone or Cort-3CMO-BSA was injected $15 \mathrm{~min}$ before behavioral testing. The control group was injected with BSA to verify the absence of any side effects of BSA alone on performance.

In a further step, anisomycin (Sigma) was dissolved in $1 \mathrm{M} \mathrm{HCl}$, diluted in saline, and adjusted to $\mathrm{pH} 7.5$ with $\mathrm{NaOH}$. The concentration of the solution was of $160 \mu \mathrm{g} / \mu \mathrm{l}$. A measure of $0.8 \mu \mathrm{l}$ of solution (corresponding to $128 \mu \mathrm{g}$ ) was injected in each hippocampus side. Anisomycin was injected in situ in the dHPC 45 min before the Cort-3CMOBSA. The control group received the anisomycin solution followed $45 \mathrm{~min}$ later by BSA.

In Experiment 3, corticosterone receptors antagonists (RU-38486 and RU-28318; Tocris, St Louis, MO) at the concentration of $20 \mathrm{mg} / \mathrm{ml}$ or vehicle (mock CSF with the addition of a small amount of absolute ethanol) were injected $15 \mathrm{~min}$ before Cort-3CMO-BSA into the dHPC. The antagonists were injected in a volume of $0.40 \mu \mathrm{l}$ per hippocampus side $(0.05 \mu \mathrm{l} / \mathrm{min}$ during $8 \mathrm{~min})$. Thus, the amounts of antagonists injected in hippocampus were eightfold higher $(8 \mu \mathrm{g})$ as compared to Cort-3CMO-BSA $(1 \mu \mathrm{g})$. A small amount of absolute ethanol was first used to dissolve the antagonists and the volumes were then brought up with mock CSF. Behavioral testing occurred 15 min after the Cort-3CMO-BSA injection.

In Experiment 4, the MR antagonist and vehicle solution were prepared similarly to Experiment 3 and injected bilaterally into the dHPC $15 \mathrm{~min}$ before stress. Behavioral testing occurred either $15 \mathrm{~min}$ ('MR antagonist + stress 15 min' group) or $60 \mathrm{~min}$ ('MR antagonist + stress $60 \mathrm{~min}$ ' group) after the acute stress delivery. They were compared to a non-stressed group receiving the vehicle solution $30 \mathrm{~min}$ before the onset of the test session or to a stressed group also receiving the vehicle solution $15 \mathrm{~min}$ before stress delivery.

\section{Microdialysis Experiments}

At least 7 days before microdialysis experiments, mice were anesthetized with a ketamine $(100 \mathrm{mg} / \mathrm{kg}$ body weight)-xylazine (10 mg/kg body weight) mixture and placed on a stereotaxic frame. A single guide microdialysis cannula (CMA/7 Microdialysis probe, CMA Microdialysis, Solna, Sweden) was implanted in the bottom of the parietal cortex at the following coordinates from the bregma (Paxinos and Franklin, 2001): antero-posterior $=-2000 \mu \mathrm{m}$; lateral $=+1400 \mu \mathrm{m}$, and vertical $=-800 \mu \mathrm{m}$. The guide cannula was fixed with dental cement and three microscrews attached to the skull. All operated mice were allowed to recover in their home cages in the animal room. On the day of the experiment, the microdialysis probe was introduced through the guide cannula and lowered $1 \mathrm{~mm}$ below so that the microdialysis membrane was located into the dorsal HPC. At the end of the microdialysis experiment, mice were anesthetized and then transcardially perfused in the left ventricle with saline solution $(\mathrm{NaCl} 0.9 \%)$, followed by formaldehyde $(4 \%)$. Brains were then post-fixed in a $4 \%$ formaldehyde solution for 10 days, and then in a saccharose-formaldehyde solution (30-4\% (v/v)) for 2 days. All the brains were coronally sectioned ( $50 \mu \mathrm{m}$ thickness). A cresyl violet stain was used to locate the microdialysis probe with utmost accuracy.

In Experiment 1, microdialysis was performed in freely moving animals to determine corticosterone levels in the dHPC after acute stress or metyrapone administration. Probes (CMA/7, membrane length $1 \mathrm{~mm}$; CMA Microdialysis) were perfused continuously with sterile filtered Dulbecco's solution at rate of $0.1 \mu \mathrm{l} / \mathrm{min}$. At $12 \mathrm{~h}$ after probe implantation and extracellular concentration equilibration ( $2 \mathrm{~h}$ at $1 \mu \mathrm{l} / \mathrm{min}$ flow rate), baseline dialysates (15 min samples) were collected with a flow rate of $1 \mu \mathrm{l} / \mathrm{min}$ during $2 \mathrm{~h}$. Intraperitoneal metyrapone injections were carried out $30 \mathrm{~min}$ before the acute stress delivery. The dialysates were collected during 3 additional hours after stress (flow rate: $1 \mu \mathrm{l} / \mathrm{min}$; sampling delay: $15 \mathrm{~min}$ ). The foot-shock delivery system was located in the dialysis cage. Samples were stored at $-80{ }^{\circ} \mathrm{C}$ before analysis. Baseline dialysates were collected for $1 \mathrm{~h}$ before intraperitoneal injection of metyrapone or vehicle, and $30 \mathrm{~min}$ before acute stress delivery. Free corticosterone levels measured in the dialysates were expressed as the percentage of the averaged baseline values sampled before the injection.

\section{Behavioral Task}

Delayed alternation procedure. All tests were performed in a T-maze constructed of gray Plexiglas. Stem and arms were $35 \mathrm{~cm}$ long, $10 \mathrm{~cm}$ wide, and $25 \mathrm{~cm}$ high. Goal arms and the start box were separated from the central alley by horizontal sliding doors. Illumination inside the apparatus (about $50 \mathrm{~lx}$ ) was provided by a lamp positioned $2 \mathrm{~m}$ above the stem. Testing was conducted between 0800 and 1200 hours to avoid circadian variations of corticosterone.

Mice were submitted to the delayed alternation task using a forced-trial procedure. In the acquisition phase, the subjects were forced to enter twice the same goal arm of the maze, as access to the other arm being blocked by the sliding door. The two forced trials were separated by a $30 \mathrm{~s}$ interval. The acquisition phase was followed by a test phase implemented $24 \mathrm{~h}$ later. During the delay separating the acquisition and test trials, mice were returned to their home cage in the animal room. During the test trial, animals 
remained $30 \mathrm{~s}$ in the start box. The door was then opened, and animals were free to enter each goal arm within the maze. The correct choice (alternation behavior) is to enter the arm opposite to that entered the day before. In all experiments, animals remained for $30 \mathrm{~s}$ in the chosen arm, and were again returned during $30 \mathrm{~s}$ to the start box, for a second free choice trial. This additional trial aimed at assessing whether the treatments impaired or not the ability of mice to alternate as well as short-term memory.

In all pharmacological and behavioral experiments, mice were subjected to two forced-trial sessions, the blocked arm of the second session being opposite to the arm blocked at the first session. Each session was separated by at least 1 week (Figure 1).

\section{Acute Stress}

The acute stress was administered $15 \mathrm{~min}$ before the test trial (first and fourth experiments). Stress was delivered in a room different from the one used for behavioral testing. Mice remained during $1 \mathrm{~min}$ in a stress delivery cage. Stressed mice received three successive unavoidable electric footshocks $(0.9 \mathrm{~mA} ; 10 \mathrm{~ms})$ in keeping with our previous studies (Celerier et al, 2004; Chauveau et al, 2010; Tronche et al, 2010). Non-stressed mice were placed in the cage in the same conditions, except that they received no footshock. Animals were then placed in their home cage for $15 \mathrm{~min}$ and subsequently assigned to the T-maze behavioral procedures.

\section{Intra-Hippocampal Corticosterone Assay}

An enzyme immunoassay commercial kit (Correlate-EIA, Assay Designs, Ann Arbor, MI) was used to measure HPC corticosterone concentrations in the microdialysates. The sensitivity of the assay was $18.6 \mathrm{pg} / \mathrm{ml}$. Therefore, baseline sample concentration was more than 10 -fold above the sensitivity threshold.

\section{Synthesis of Cort-3CMO-BSA}

Chemicals and experimental equipment. Corticosterone $(+97.0 \%)$ and carboxymethoxylamine hemihydrochloride $(+98.0 \%)$ were purchased from TCI Europe (Zwinjndrecht, Belgium). Anhydrous pyridine (99.8\%), dichloromethane,

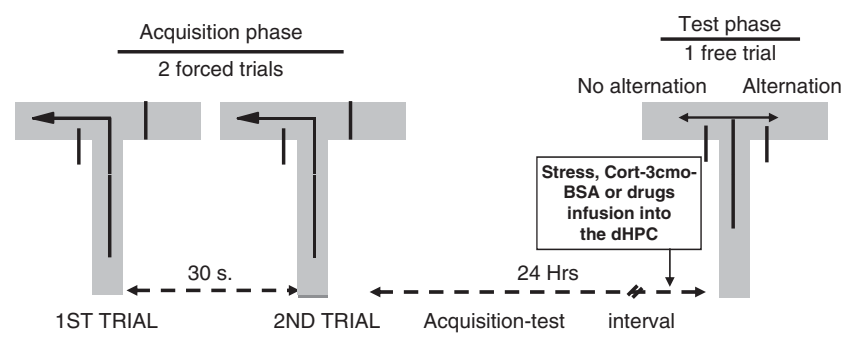

Figure I Memory testing procedure: animals are first submitted to an acquisition phase in which they are forced to enter twice the same arm of the maze (two forced trials); then, after a 24-h delay interval, they are submitted to the test phase in which they can freely enter either arm of the maze. An alternation is scored when the mouse enters the arm opposite to the one visited in the acquisition phase. Treatments (stress, and drug infusions in the (HPC) are delivered before the test phase, according to the experimental schedule described in the Materials and methods section. and methanol (Chromasolv grade) were supplied by SigmaAldrich Chemicals (Saint Quentin Fallavier, France). ${ }^{1} \mathrm{H}$ and ${ }^{13} \mathrm{C}$ NMR spectra were recorded with a Bruker AC-300 FT $\left({ }^{1} \mathrm{H}: 300 \mathrm{MHz} ;{ }^{13} \mathrm{C}: 75 \mathrm{MHz}\right)$. Chemical shifts $(\delta)$ and coupling constants $(J)$ are expressed in p.p.m. and $\mathrm{Hz}$, respectively. High-resolution mass spectrum was acquired by the CESAMO (Bordeaux, France) on a QStar Elite mass spectrometer (Applied Biosystems). Thin-layer chromatography (TLC) was performed on SDS TLC plates: thickness $0.25 \mathrm{~mm}$, particle size $15 \mu \mathrm{m}$, and pore size $60 \AA$. Merck silica gel $60(70-230$ mesh and $0.063-0.200 \mathrm{~mm})$ was used for flash chromatography. Spots were revealed with UV as well as $\mathrm{KMnO}_{4}(0.05 \%$ in water $)$.

Synthesis of Cort-3CMO. A solution of carboxymethoxylamine hemihydrochloride $(82 \mathrm{mg}, 0.75 \mathrm{mmol})$ and anhydrous pyridine $(79 \mathrm{mg}, 80 \mu \mathrm{l}, 1 \mathrm{mmol})$ in methanol $(5 \mathrm{ml})$ was added to a solution of corticosterone (173 mg, $0.5 \mathrm{mmol})$ in methanol $(4 \mathrm{ml})$ at room temperature. The mixture was stirred for $5 \mathrm{~h}$ and concentrated under reduced pressure. The residue was purified by flash silica gel chromatography, using dichloromethane/methanol (94:6 $(\mathrm{v} / \mathrm{v}))$ as an eluent, to afford the target compound as a white solid (157 mg, 75\%, + $95 \%$ purity by NMR, Rf=0.15).

${ }^{1} \mathrm{H}$ NMR (MeOH-D4) $\delta 0.91\left(\mathrm{~s}, 3 \mathrm{H}, \mathrm{CH}_{3}-18\right), 0.91-1.22$ (m, 3H, $\left.\mathrm{CH}_{2}-7 \mathrm{~b}, \mathrm{CH}-9, \mathrm{CH}-14\right)$, 1.37 (s, 3H, $\left.\mathrm{CH}_{3}-19\right)$, 1.511.85 (m, 5H, $\left.\mathrm{CH}_{2}-1 \mathrm{~b}, \mathrm{CH}_{2}-12 \mathrm{~b}, \mathrm{CH}_{2}-15, \mathrm{CH}_{2}-16 \mathrm{~b}\right), 1.91-2.55$ (m, 9H, $\mathrm{CH}_{2}-1 \mathrm{a}, \mathrm{CH}_{2}-2 \mathrm{~b}, \mathrm{CH}_{2}-6, \mathrm{CH}_{2}-7 \mathrm{a}, \mathrm{CH}-8, \mathrm{CH}_{2}-12 \mathrm{a}$, $\mathrm{CH}_{2}-16 \mathrm{a}, \mathrm{CH}-17$ ), 3.02 (apparent $\mathrm{dt}, 1 \mathrm{H}, \mathrm{J}=17$ and $4 \mathrm{~Hz}$, $\left.\mathrm{CH}_{2}-2 \mathrm{a}\right), 4.15$ (d, $\left.1 \mathrm{H}, J=19 \mathrm{~Hz}, \mathrm{CH}_{2}-21 \mathrm{a}\right), 4.23$ (d, $1 \mathrm{H}$, $\left.J=19 \mathrm{~Hz}, \mathrm{CH}_{2}-21 \mathrm{~b}\right), 4.34(\mathrm{~m}, 1 \mathrm{H}, \mathrm{CH}-11), 4.56$ (s, $2 \mathrm{H}$, $\left.\mathrm{O}-\mathrm{CH}_{2}-\mathrm{COOH}\right)$, and $5.66(\mathrm{~s}, 1 \mathrm{H}, \mathrm{CH}-4)$.

${ }^{13} \mathrm{C}$ NMR (MeOH-D4) $\delta 15.0\left(\mathrm{CH}_{3}-18\right), 18.9\left(\mathrm{CH}_{2}-2\right), 20.4$ $\left(\mathrm{CH}_{3}-19\right), 22.0\left(\mathrm{CH}_{2}-16\right), 24.1\left(\mathrm{CH}_{2}-15\right), 31.4\left(\mathrm{CH}_{2}-6\right), 31.9$ (CH-8), $33.0\left(\mathrm{CH}_{2}-7\right), 33.7\left(\mathrm{CH}_{2}-1\right), 38.5$ (C-10), 43.5 (C-13), $47.7\left(\mathrm{CH}_{2}-12\right), 56.5$ (CH-9), 57.7 (CH-14), 59.0 (CH-17), 67.0 $(\mathrm{CH}-11), 68.6\left(\mathrm{CH}_{2}-21\right), 69.7\left(\mathrm{O}-\mathrm{CH}_{2}-\mathrm{COOH}\right), 114.5(\mathrm{CH}-4)$, 157.9 (C-3), $161.7(\mathrm{C}-5), 172.8(\mathrm{COOH})$, and 210.4 (C-20).

HR-MS (ESI + ): $m / z 442.2200$ for $[\mathrm{M}+\mathrm{Na}]^{+}$(calcd for $\left.\left[\mathrm{C}_{23} \mathrm{H}_{33} \mathrm{NO}_{6} \mathrm{Na}\right]^{+}, 442.2206\right)$.

Synthesis of Cort-3CMO-BSA conjugate. Cort-3CMO was coupled to BSA by the activated ester method. Briefly, 1(3-dimethyaminopropyl)-3-ethylcarbodiimide hydrochloride ( $21 \mathrm{mg}, 110 \mu \mathrm{mol}, 1.1$ equiv.) and $N$-hydroxysuccinimide ( $12.7 \mathrm{mg}, 110 \mu \mathrm{mol}, 1.1$ equiv) were added to a solution of Cort-3CMO (42 mg, $100 \mu \mathrm{mol}, 50$ equiv.) in anhydrous DMF $(2 \mathrm{ml})$ at $0{ }^{\circ} \mathrm{C}$. The mixture was stirred for $2 \mathrm{~h}$ and was then added to an ice-cooled solution of BSA (134 mg, $2 \mu \mathrm{mol})$ in $0.2 \mathrm{M}$ borate-boric buffer, $\mathrm{pH} 8.7(5 \mathrm{ml})$. The resulting mixture was allowed to warm at room temperature for $6 \mathrm{~h}$, and then dialyzed against phosphate buffer saline $(0.01 \mathrm{M}$, pH 7.4, 0.9\% NaCl) and distilled water. The Cort-3CMOBSA conjugate was lyophilized and stored at $-20^{\circ} \mathrm{C}$. The corticosterone density on BSA was analyzed by matrixassisted laser desorption-ionization mass spectrometry (MALDI-MS). The molecular ratio of covalently linked corticosterone was about 30 per molecule of BSA.

Stability of Cort-3CMO-BSA conjugate. To verify the stability of Cort-3CMO-BSA once administered in vivo, we diluted Cort-3CMO-BSA in mouse CSF at the concentration 
of $1 \mathrm{mg} / \mathrm{ml}$. Mouse CSF was sampled on 12 mice according to the technique described by Liu and Duff (2008). We analyzed the solution after 15,60 , and $120 \mathrm{~min}$ at a thermostated temperature of $37^{\circ} \mathrm{C}$. The solution was analyzed using ELISA technique (Arbor assays), allowing determination of only free corticosterone but not of conjugated forms. In each solution, free corticosterone concentrations were inferior to the limit of detection of the technique $(16.9 \mathrm{pg} / \mathrm{ml})$. Thus, we can assume that after $2 \mathrm{~h}$ in CSF at $37^{\circ} \mathrm{C}$, the concentration of free corticosterone was inferior to 0.0169 p.p.m. In consequence, the Cort-3CMOBSA complex appears to be stable once administered in vivo.

\section{Statistical Analysis}

Statistical analyses were performed using the Statview 5.0 software. The data were analyzed using one- or two-way factorial analyses of variance (ANOVAs), followed, when adequate, by post hoc comparisons (Scheffe's test). Data were expressed as means \pm SEM. Comparisons of retrieval performances with chance level were calculated with one-sample Student's $t$-test (with hypothesized mean $=$ chance level $=50 \%$ ). Microdialysis data were analyzed using one- or two-way repeated-measure ANOVA as appropriate, followed, when adequate, by post hoc testing (Bonferroni's test).

\section{RESULTS}

\section{First Experiment: Effects of Acute Stress and Metyrapone on Delayed Alternation Rates and Hippocampal Corticosterone Concentrations}

Effects of acute stress delivered $15 \mathrm{~min}$ before test session. Data are represented in Figure 2a. The data revealed a a

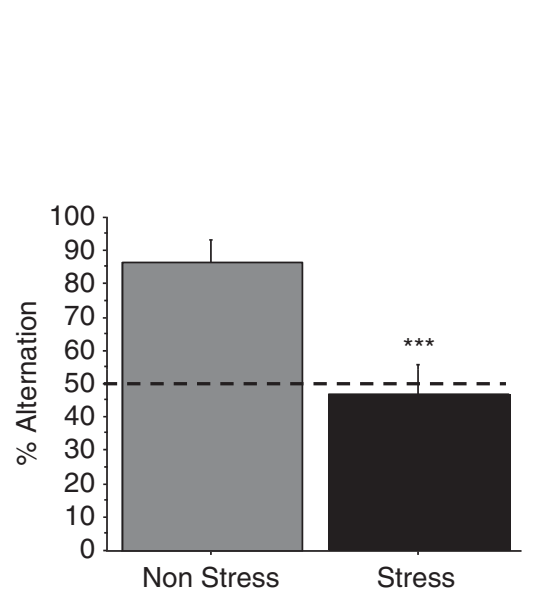

C b

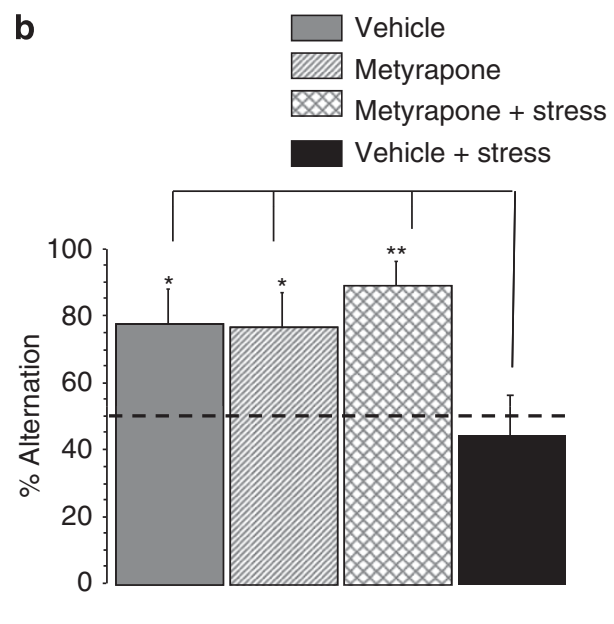

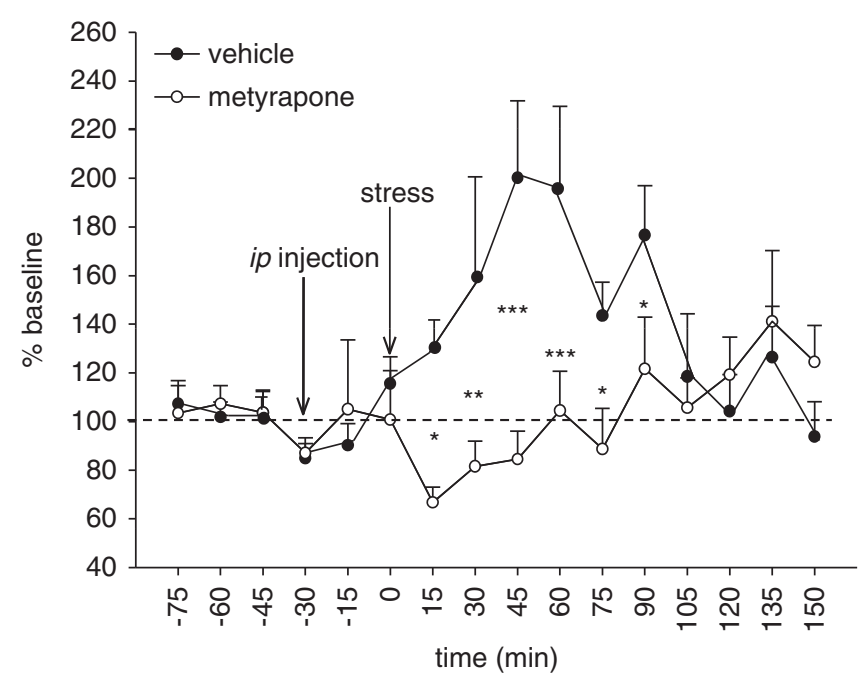

Figure 2 (a) Effects of stress on delayed alternation performance. Stress, delivered 15 min before test session, significantly reduced alternation rates: **** $<0.00$ I; chance level: $50 \%$. (b) Effects of stress and metyrapone (inhibitor of corticosterone synthesis) on delayed alternation rates. Metyrapone $(35 \mathrm{mg} / \mathrm{kg}$ ) injected intraperitoneally 30 min before stress delivery blocked the deleterious effects of stress on alternation rates; * $p<0.05$; ** $p<0.01$; chance level: $50 \%$. (c) Time-course evolution of corticosterone in the dorsal hippocampus measured by microdialysis in stressed animals pretreated or not with metyrapone $(35 \mathrm{mg} / \mathrm{kg}$ ). The peak of corticosterone is observed at about $60 \mathrm{~min}$ and return to baseline at about 90 min after stress delivery. Results are expressed in relative concentration; comparison to baseline: $* p<0.05$; $* * 0.0$ I; ${ }^{* * * *} p<0.00$ I. Metyrapone-treated mice exhibit no difference after stress delivery as compared to baseline for each time. 
significant between-group difference $(\mathrm{F}(1,58)=12.7$; $p=0.0007)$. More precisely, non-stressed mice $(N=30)$ exhibited alternation rates $(86.6 \pm 6.3 \%)$ significantly above those observed in stressed ones $(N=30 ; 46.6 \pm$ $9.2 \%)$. In contrast, both groups exhibited similar short-term alternation rates evaluated $30 \mathrm{~s}$ after the delayed test session $(90.0 \pm 5.5 \%$ vs $80.0 \pm 7.4 \%$ for nonstressed and stressed groups respectively; $\mathrm{F}(1,58)=1.16$; $p=0.28)$.

Effects of metyrapone administered $30 \mathrm{~min}$ before acute stress on delayed alternation rate. Data are presented in Figure $2 \mathrm{~b}$. The data revealed a significant between-group difference $(\mathrm{F}(3,67)=3.5 ; p=0.018)$. More specifically, whereas vehicle $(N=18 ; 77.7 \pm 10.0 \%)$, metyrapone $(N=17 ; 76.4 \pm 10.6 \%)$, and metyrapone + stress $(N=18$; $88.8 \pm 7.6 \%)$ groups exhibited similar performances (NS in all comparisons), the stressed group $(N=18)$ displayed significantly lower performances $(44.4 \pm 12 \%)$ as compared to vehicle and metyrapone groups $(p<0.05$ in both comparisons) and as compared to the metyrapone + stress group $(p<0.01)$.

In contrast, all groups exhibited similar short-term alternation rates evaluated $30 \mathrm{~s}$ after the 24 -h delayed test session $(83.3 \pm 9.0 \%, 76.4 \pm 10.0 \%, 77.7 \pm 10.0 \%$, and $88.8 \pm 7.6 \%$ for vehicle, metyrapone, vehicle + stress, and metyrapone + stress groups, respectively; $F(1,58)=1.16$; $p=0.28)$.

Stress-induced intra-hippocampus corticosterone rise. Figure $2 c$ represents corticosterone levels in the dHPC. Results are expressed in percentage of variation of baseline. Two-way repeated-measure ANOVAs performed on corticosterone kinetic evidenced a significant interaction between Treatments $\times$ Time $(\mathrm{F}(15,180)=3.275 ; p \leqslant 0.001)$. Bonferroni's $t$-test did not reveal any differences between the groups (vehicle: $N=8$; metyrapone: $N=8$ ) in the prestress period for each factor.

Vehicle As compared to the last pre-stress sample $(108.66 \pm 10.98 \%$; 'time $=0$ '), stress induced a progressive and significant increase in corticosterone levels from $15 \mathrm{~min} \quad(131.32 \pm 8.23 \% ; \quad t=2.99 ; p \leqslant 0.05)$ to $90 \mathrm{~min}$ $(179.75 \pm 21.32 \% ; \quad t=2.992 ; p \leqslant 0.05)$. Furthermore, the highest difference was observed $60 \mathrm{~min}$ after stress administration $(200.24 \pm 31.63 ; t=4.062 ; p \leqslant 0.001)$.

Metyrapone As compared to the last pre-stress sample $(102.86 \pm 21.04 \%$; 'time $=0$ '), the stress-induced increase in corticosterone levels observed in vehicle-treated mice was not observed in metyrapone-treated ones. As a consequence, the progressive and significant increase in corticosterone levels in vehicle-treated mice was observed 15-90 min after stress delivery, as compared to metyrapone-treated mice ( $15 \mathrm{~min}$ post-stress delay: $131.32 \pm 8.23 \%$ and $68 \pm 3.5 \%$, respectively; $t=3.96 ; p=0.03 ; 90 \mathrm{~min}$ post-stress delay: $179.75 \pm 21.32 \% \quad$ vs $122 \pm 20.5 \% ; \quad t=2.96 ; \quad p<0.05)$. Finally, no significant difference was observed between vehicle- and metyrapone-treated mice from the $105 \mathrm{~min}$ post-stress delay point $(118.50 \pm 25.79 \%$ and $105.75 \pm$ $12.19 \%$ respectively; $t=0.476$; NS) up to the $150 \mathrm{~min}$ point $(93.89 \pm 14.25 \%$ and $124.49 \pm 14.99 \%$, respectively; $t=1.143$; NS).
Second Experiment: Effects of Intra-Hippocampus Corticosterone or Cort-3CMO-BSA Injections on Delayed Alternation Rates

Effects of intra-hippocampus corticosterone injection. Data are presented in Figure $3 \mathrm{a}$. The data revealed a significant between-group difference $(\mathrm{F}(2,57)=4.3 ; p=0.018)$. More precisely, whereas non-operated $(N=20 ; 75.0 \pm 9.9 \%)$ and sham-operated + vehicle $(N=20 ; 85.0 \pm 8.2 \%)$ groups exhibited similar performances (NS), the corticosterone-injected group exhibited significantly lower performances $(N=20$; $44.4 \pm 12 \%)$ as compared to non-operated $(p<0.05)$ and sham-operated + vehicle $(p<0.01)$ groups.

In contrast, all groups exhibited similar short-term alternation rates evaluated $30 \mathrm{~s}$ after the 24-h delayed test session $(85.0 \pm 8.1 \%, 75.0 \pm 9.9 \%$, and $80.0 \pm 9.1 \%$ for, respectively, non-operated, sham-operated + vehicle, and corticosterone groups; $\mathrm{F}(2,57)<1.0)$.

Effects of intra-hippocampus Cort-3CMO-BSA injection. Data are displayed in Figure $3 \mathrm{~b}$. The data revealed a significant between-group difference $(\mathrm{F}(2,33)=5.31$; $p=0.008)$. More pointedly, whereas non-operated $(72.9 \pm$ $4.7 \%)$ and BSA-injected $(71.1 \pm 5.1 \%)$ groups exhibited similar performances (NS), the Cort-3CMO-BSA-injected group exhibited significantly lower performances $(40.1 \pm 5.4 \%)$ as compared to the two other groups $(p<0.01$ in both comparisons).

In contrast, all groups exhibited similar short-term alternation rates evaluated $30 \mathrm{~s}$ after the delayed test session $(80.8 \pm 5.1 \%, 70.0 \pm 8.2 \%$, and $75 \pm 4.1 \%$ for, respectively, non-operated, sham-operated + vehicle, and corticosterone groups; $\mathrm{F}(2,57)<1.0)$.

Effects of anisomycin administered before Cort-3CMO$B S A$. Data are displayed in Figure 3c. The data revealed a significant between-group difference $(\mathrm{F}(1,22)=5.90$; $p=0.023)$. More pointedly, whereas anisomycin + BSAinjected mice $(N=12)$ exhibited a high level of alternation performance $(79.2 \pm 11.4 \%)$, anisomycin + Cort-3CMOBSA-treated mice $(N=12)$ showed a significant decrease in alternation performance $(41.6 \pm 10.3 \%$; $p<0.05)$ In contrast, all groups exhibited similar short-term alternation rates evaluated $30 \mathrm{~s}$ after the delayed test session $(75.0 \pm 9.7 \%$ and $87.5 \pm 6.5 \%$ for, respectively, anisomycin + BSA and anisomycin + Cort-3CMO-BSA, respectively; $\mathrm{F}(1,22)=1.13 ; p=0.29)$.

\section{Third Experiment: Effects of Intra-Hippocampus MR or GR Antagonists Administered Alone or with Cort- 3CMO-BSA on Delayed Alternation Rates}

Effects of intra-hippocampus $M R$ or GR antagonists on delayed alternation rates. Data are represented in Figure $4 \mathrm{a}$. The data revealed a nonsignificant betweengroup difference $(\mathrm{F}(3,44)<1.0)$. Performance of nonoperated group $(N=14 ; 85.7 \pm 9.7 \%)$ were similar to that of vehicle-injected mice $(N=14 ; 75 \pm 13.0 \%)$ and to groups receiving either $\mathrm{MR}(N=10 ; 80 \pm 8.1 \%)$ or GR antagonists $(N=10 ; 75 \pm 8.3 \%)$.

All groups exhibited similar short-term alternation rates evaluated $30 \mathrm{~s}$ after the 24 -h delayed test session 
a

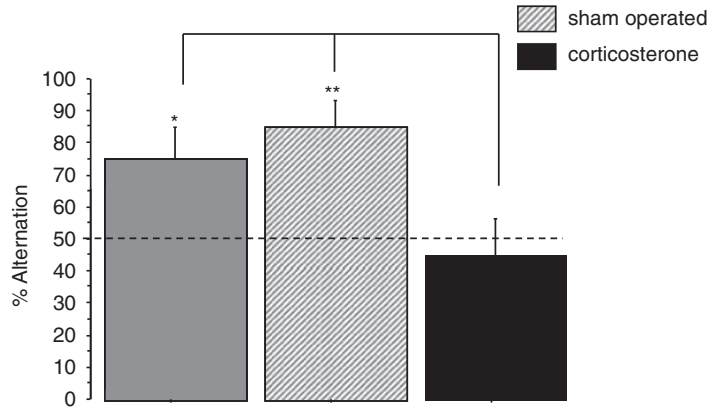

b

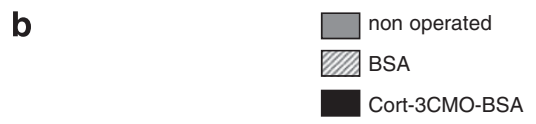

C

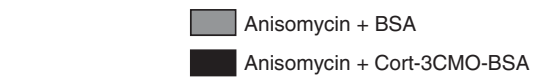

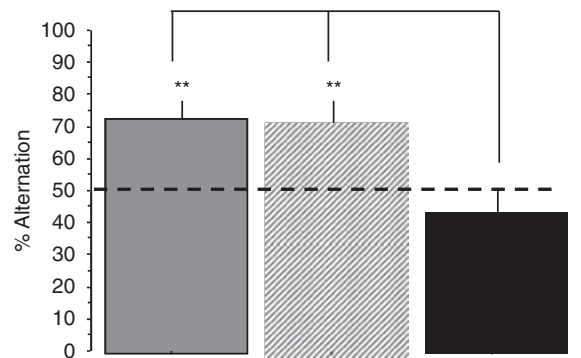

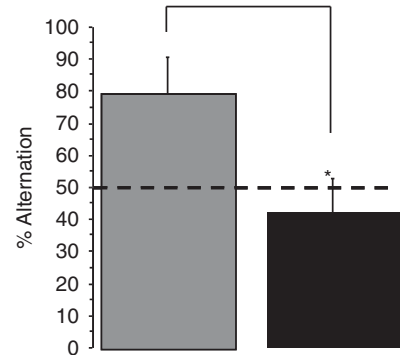

Figure 3 (a) Effect of corticosterone on delayed alternation performance. Corticosterone $(\mathrm{I} \mathrm{mg} / \mathrm{ml})$ was bilaterally injected in the dorsal hippocampus 15 min before the test session. Control groups were either non-operated or received the vehicle solution. Corticosterone reduced alternation rates significantly as compared to control groups; $* p<0.05$; ** $p<0.0$ I. (b) Effect of Cort-3CMO-BSA (corticosterone-3-O-carboxymethyloxime-BSA conjugate) on delayed alternation performance. Cort-3CMO-BSA $(I \mathrm{mg} / \mathrm{ml})$ was bilaterally injected in the dorsal hippocampus $15 \mathrm{~min}$ before the test session. Control groups were either non-operated animals or animals receiving BSA only to verify the absence of any side effect of BSA alone on performance. Cort-3CMO-BSA reduced alternation rates significantly as compared to control groups; ** $<0.0$ I; chance level: $50 \%$. (c) Effect of anisomycin administered in dorsal hippocampus 45 min before Cort-3CMO-BSA on delayed alternation performance. Anisomycin (I $28 \mu \mathrm{g}$ per side) failed to block the deleterious effects of Cort-3CMO-BSA $(I \mathrm{mg} / \mathrm{ml})$ bilaterally injected in the dorsal hippocampus 15 min before the test session. *p $<0.05$.

$(85.7 \pm 9.7 \%, 78.6 \pm 11.4 \%, 80.0 \pm 13.3 \%$, and $88.7 \pm 6.3 \%$ for non-operated, vehicle, MR, and GR antagonists groups, respectively; $\mathrm{F}(3,44)<1.0)$.

Effects of intra-hippocampus $M R$ or GR antagonists administered before Cort-3CMO-BSA on delayed alternation rates. Data are represented in Figure $4 \mathrm{~b}$. The data revealed a significant between-group difference $(\mathrm{F}(3,58)=5.48 ; p=0.002)$. Significant between-group differences were observed between performance of vehicle + Cort-3CMO-BSA-injected mice $(N=12 ; 33.3 \pm 14.2 \%)$ as compared to vehicle + vehicle group $(N=12 ; 70.8 \pm 12.9 \%$; $p<0.02)$ and to MR antagonist + Cort-3CMO-BSA group $(N=16 ; 84.4 \pm 6.0 \% ; p<0.002)$. In contrast, no significant difference was observed between the GR antagonist + Cort-3CMO-BSA group $(N=22 ; 43.2 \pm 8.9 \%)$ and vehicle + Cort-3CMO-BSA-injected mice $(33.3 \pm 14.2 \%$; NS).

All groups exhibited similar short-term alternation rates evaluated $30 \mathrm{~s}$ after the 24-h delayed test session $(83.3 \pm 11.2 \%, 75.0 \pm 13.0 \%, 81.8 \pm 8.4 \%$, and $87.5 \pm 8.5 \%$ for vehicle + vehicle, vehicle + Cort-3CMO-BSA, GR antagonist + Cort-3CMO-BSA, and MR antagonist + Cort$3 \mathrm{CMO}-\mathrm{BSA}$ groups, respectively; $\mathrm{F}(3,58)<1.0)$.
Fourth Experiment: Effects of Intra-Hippocampus MR Antagonist Administered before Acute Stress Delivery on Delayed Alternation Evaluated Either 15 or 60 min After Stress Delivery

Data are represented in Figure 5. The data revealed a significant between-group difference $(F(3,90)=5.78$; $p=0.001)$. Significant between-group differences were observed between the non-stressed vehicle group $(N=21$; $80.9 \pm 8.7 \%)$ and the vehicle + stress group $(N=20$; $30.0 \pm 10.5 \% ; p<0.001)$. Moreover, the performance in 'MR antagonist + stress 15 min' group $(N=25$; $68.0 \pm 9.5 \%$ ) was significantly different as compared to the vehicle stressed group $(p<0.01)$, but did not differ from that of the vehicle-injected mice (NS). However, performance of the MR antagonist + stress 60 min group $(N=28$; $39.2 \pm 9.3 \%$ ) did not differ from that of stressed mice (NS), but were significantly lower as compared to both the MR antagonist + stress $15 \mathrm{~min}$ group $(p=0.02)$ and the nonstressed vehicle one $(p=0.002)$

All groups exhibited similar short-term alternation rates evaluated $30 \mathrm{~s}$ after the delayed test session $(\mathrm{F}(3,90)<1.0$; vehicle: $66.6 \pm 10.5 \%$; vehicle + stress: $70.0 \pm 10.5 \%$; 'MR antagonist + stress 15 min': $68.0 \pm 9.5 \%$; 'MR antagonist + stress 60 min': $67.8 \pm 8.9 \%$ ). 
a
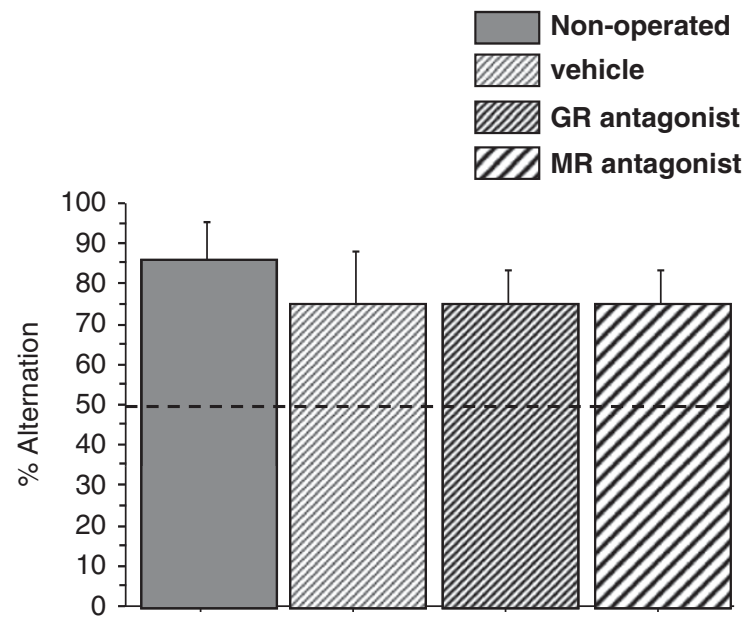

b
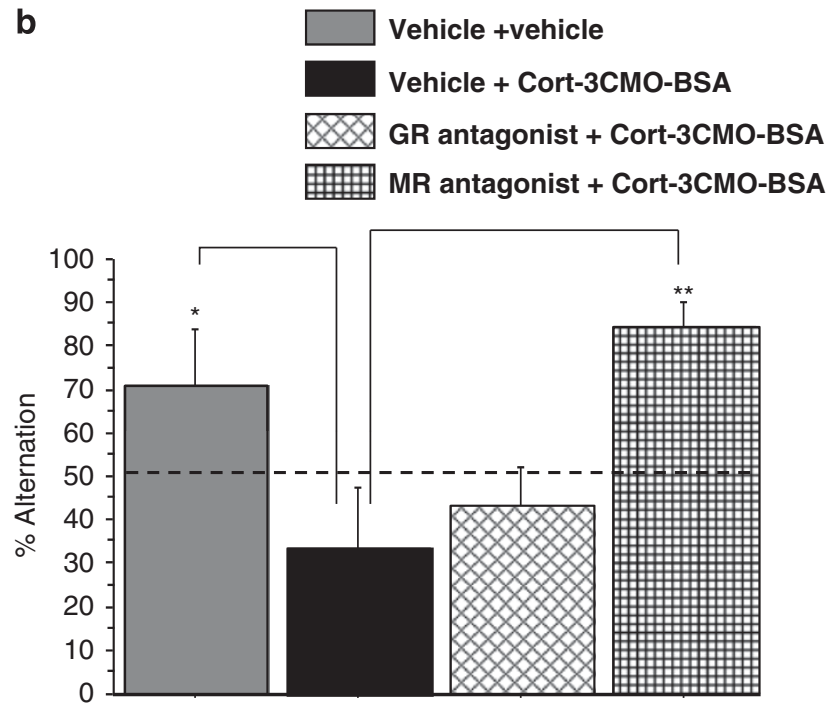

Figure 4 (a) Effects of glucocorticoid receptor (GR) antagonist (RU38486 or mifepristone) and mineralocorticoid receptor (MR) antagonist (RU-283|8) on delayed alternation rates. Both antagonists were injected bilaterally in the dorsal hippocampus at the dose of $20 \mu \mathrm{g} / \mathrm{ml}$ each $15 \mathrm{~min}$ before behavioral testing. Control groups were either non-operated animals or animals receiving vehicle only. The administration of both antagonists did not significantly modify alternation rates as compared to control groups. Chance level: 50\%. (b) Effects of GR antagonist (RU-38486 or mifepristone) and MR antagonist (RU-283/8) and Cort-3CMO-BSA (corticosterone-3-O-carboxymethyloxime-BSA conjugate) on delayed alternation rates. Both antagonists were injected bilaterally in the dorsal hippocampus at the dose of $50 \mathrm{ng} / \mathrm{ml}$ each $15 \mathrm{~min}$ before the Cort3CMO-BSA injection ( $\mathrm{mg} / \mathrm{ml})$. Behavioral testing occurred $15 \mathrm{~min}$ after Cort-3CMO-BSA injection. Control groups were either animals receiving two vehicle injections separated by $15 \mathrm{~min}$ or animals receiving vehicle, followed I 5 min later by Cort-3CMO-BSA injection. Results showed that the $\mathrm{MR}$ antagonist blocked the memory impairment observed in animals receiving Cort-3CMO-BSA only; in contrast, the GR antagonist did not block the deleterious effects of Cort-3CMO-BSA injection on alternation rates. Comparisons to Cort-3CMO-BSA-treated animals: ${ }^{*} p<0.05$; *** $<0.0$ I; chance level: $50 \%$.

\section{Histological Analysis}

Figure 6 shows the anterograde extent and the localization of the cannulae tips in the dHPC of mice. Black zones: main implantation sites; and black hashed areas: antero-retrograde extent of the cannulae tips implantation.
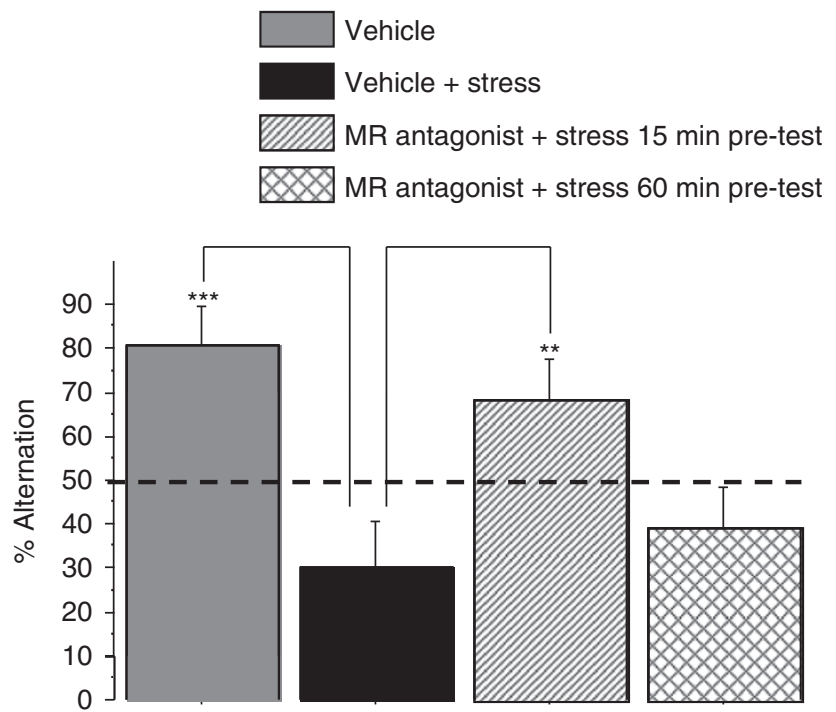

Figure 5 Effects of mineralocorticoid receptor (MR) antagonist (RU-283/8) administered into the dorsal hippocampus $15 \mathrm{~min}$ before acute stress on delayed alternation rates. Behavioral test session occurred either 15 or $60 \mathrm{~min}$ after stress. Control groups were animals receiving vehicle only, followed or not by acute stress. The administration of the MR antagonist at the dose of $20 \mu \mathrm{g} / \mathrm{ml}$ blocked the stress-induced impairment on alternation rates $15 \mathrm{~min}$ but not $60 \mathrm{~min}$ after stress delivery. Comparisons to vehicle stressed animals: $* * * 0.01$; **** $p<0.00$ I; chance level: $50 \%$.
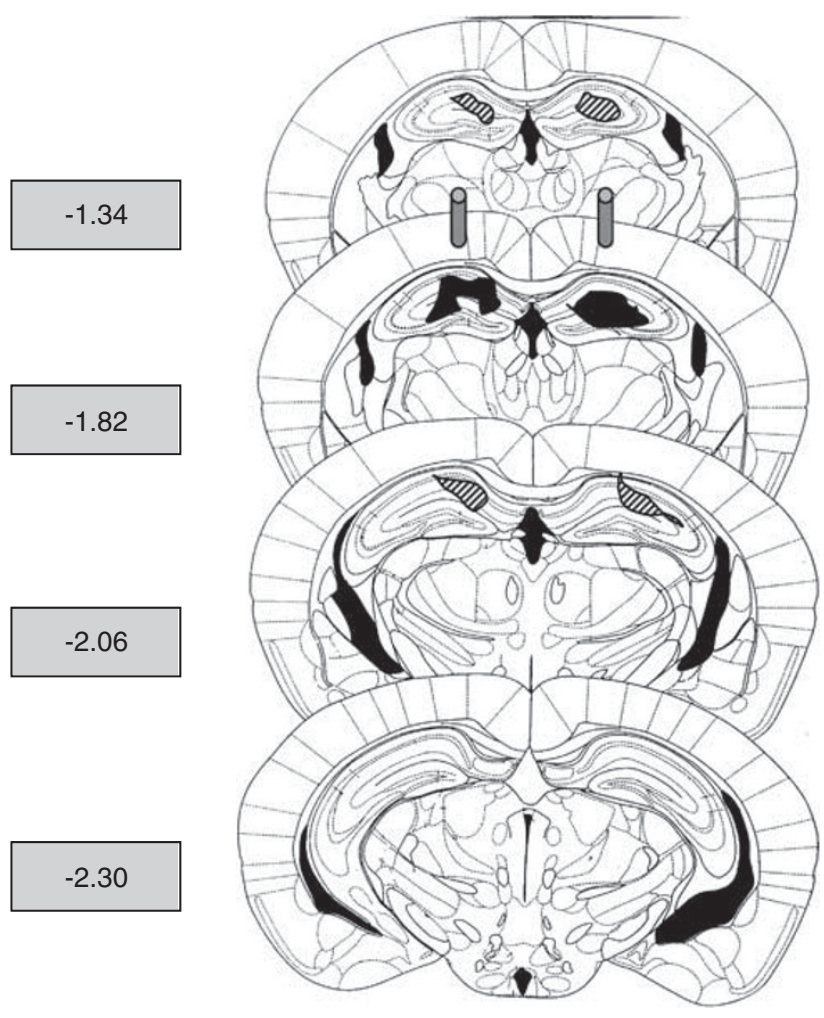

Figure 6 Representative localization of the sites of drug injections into the dorsal hippocampus. Reconstruction of the main sites of drug injections (black areas) and antero-posterior extent of the sites of injections (black hashed areas). Stereotaxic rostro-caudal coordinates are mentioned in $\mathrm{mm}$ from bregma. 


\section{DISCUSSION}

The main findings of the study are as follows: in a first experiment, we evidenced that an acute stress (electric footshocks) induced both a dHPC corticosterone rise measured by microdialysis and a memory retrieval impairment in a non-rewarded spontaneous delayed alternation task. In addition, both the endocrinal and memory retrieval effects of stress were blocked by metyrapone (a corticosterone synthesis inhibitor; de Quervain et al, 1998; Roozendaal et al, 2001). In a second experiment, we showed that bilateral dHPC injections of either corticosterone or Cort3CMO-BSA $15 \mathrm{~min}$ before memory retrieval produced impairments similar to those resulting from acute stress. Furthermore, we showed that anisomycin (a protein synthesis inhibitor) failed to block the deleterious effect of Cort-3CMO-BSA on memory. In a third experiment, we demonstrated that bilateral intra-hippocampal injection of RU-28318 (an MR antagonist) but not of RU-38486 (a GR antagonist) totally blocked the Cort-3CMO-BSA-induced memory retrieval deficit. In a fourth experiment, we found that the MR antagonist RU-28318 administered $15 \mathrm{~min}$ before acute stress blocked the stress-induced memory impairments when test occurred $15 \mathrm{~min}$ but not $60 \mathrm{~min}$ after stress delivery.

Overall, this study provides the first in vivo evidence that the dHPC membrane GRs involved in the rapid and non-genomic effects of acute stress on memory retrieval are of MR type.

The findings of the first two experiments are congruent with our previous study showing memory retrieval impairments associated to dHPC corticosterone rise $15 \mathrm{~min}$ but not $120 \mathrm{~min}$ after acute stress delivery (Chauveau et al, 2010; Tronche et al, 2010). Moreover, earlier studies stemming from our research team showed that stress effects on memory are only transient and were observed $15 \mathrm{~min}$ but not $120 \mathrm{~min}$ after stress delivery (Celerier et al, 2004). As Cort-3CMO-BSA - a high MW complex that cannot cross biological membranes and stable in physiological conditions-produced deleterious effects on memory retrieval similar to those resulting from acute stress or dHPC corticosterone injections, we can conclude that the rapid effects of stress are mediated by membrane GRs (see Chauveau et al, 2010). This finding is sustained by the fact that anisomycin (a protein synthesis inhibitor) was unable to block the deleterious effect of Cort-3CMO-BSA on memory retrieval (see Figure $3 b$ and $c$ ). The lack of deleterious effect of anisomycin itself on memory retrieval is in agreement with studies showing that anisomycin impairs consolidation and reconsolidation processes that involve transcriptional factors (Stafford and Lattal, 2009). In contrast, in our experiment, anisomycin was administered just before the retrieval session, that is, $24 \mathrm{~h}$ after the acquisition of the to-be remembered information. Moreover, a genomic effect of stress or Cort-3CMO-BSA was unlikely because we evaluated memory retrieval $15 \mathrm{~min}$ after treatments, a time interval that excludes a genomic action that requires more than $30 \mathrm{~min}$ to develop (Sapolsky et al, 2000).

Surprisingly, corticosterone covalently bound to a protein has been seldom used to evaluate the membrane effects of GCs on cognitive processes (Chauveau et al,
2010; Barsegyan et al, 2010). In this study, we synthesized, purified, and characterized Cort-3CMO-BSA. Repetitive dialysis was applied to eliminate non-reacted corticosterone and MALDI-MS was used to determine the binding efficiency of corticosterone-protein conjugate (number of covalently bound corticosterone entities per protein molecule, that is, $30: 1$ ). This well-characterized home-made Cort-BSA complex, totally devoid of free corticosterone and found to be stable in physiological conditions, allowed us to investigate the effects of membrane GRs activation.

In a further step, we attempted to characterize the type (MR vs GR) of GC membrane receptors involved in the rapid modulation of memory retrieval induced by stress or Cort-3CMO-BSA. Thus, this study demonstrated that GRs of MR type in the dHPC are responsible for these effects. Indeed, RU-28318, an MR antagonist, blocked the deleterious effects of Cort-3CMO-BSA or stress-induced dHPC corticosterone rise on memory retrieval. In contrast, RU-38486 (mifeprisone), a GR antagonist, was unable to counteract such effects. Thus, this study provides pharmacological direct evidence that the membrane dHPC GRs responsible for the rapid cognitive impairments of stress and corticosterone on memory retrieval are of MR but not GR type (for a review, see Joels et al, 2007).

It has already been suggested that central MRs are indispensable for corticosterone-induced impairment of memory retrieval in rats. Thus, Khaksari et al (2007) evidenced a non-genomic effect of corticosterone on memory retrieval using anisomycin. However, in contrast to this study, their data did not directly demonstrate the involvement of MR at membrane level. Moreover, in their study, the GC antagonists were injected intracerebroventricularly, precluding identification of the brain areas sustaining the pharmacological effects, as opposed to this study. Our current data however apparently contrast with recent findings from Barsegyan et al (2010), who showed that Cort-BSA injected into the medial prefrontal cortex facilitated memory consolidation of emotional experiences and concurrently impaired working memory in a rewarded sequential alternation task in rats. In their study, these effects were antagonized by GR but not MR antagonists. Their pharmacological design differs from ours however as regards the brain site of drug injections and the time of drug injections before memory testing, that is, $60 \mathrm{~min}$. Indeed, this delay can neither exclude a non-genomic mechanism nor the possible involvement of GRs. The results provided by the fourth experiment of this study clearly indicate that the injection of MR antagonist is unable to block the stress-induced memory retrieval impairment when the test session occurred $60 \mathrm{~min}$ after stress delivery. Interestingly, we showed in the first experiment (see Figure 2c) that the maximum level of corticosterone rise in dHPC is observed about $60 \mathrm{~min}$ after stress delivery. Therefore, one can suggest that the lack of effect of the MR antagonist RU-28318 on memory retrieval performance in stressed animals at the 60 min interval could rely on either an action of corticosterone on cytosolic receptors or an involvement of GRs, which exhibit low affinity for corticosterone, thus requiring high corticosterone concentration to be activated (for a review see Joëls, 2008). The latter hypothesis fits well with the high corticosterone level observed in the dHPC $60 \mathrm{~min}$ after stress delivery. Indeed, 
our data obtained with the MR antagonist at $60 \mathrm{~min}$ is in agreement with the findings of Barsegyan et al (2010), which evidenced that $M R$ receptors are not involved on memory performance at this delay interval. In agreement with the study of Joels et al (2007), it can be suggested that low-affinity membrane version of the MR contributes to the initial phase of the stress reaction, followed by the GR involvement, which terminates the stress response.

Another finding within our study is that short-term memory (assessed by the second free choice trial of the test session procedure) was unaffected by stress, corticosterone, or GC antagonists administration. The effects of GCs on short-term memory are variable and depend on several factors such as the kind of task, the type of stressors, the brain structures sustaining task performances, and so on (Barsegyan et al, 2010; Yehuda et al, 2007; Brunner et al, 2006). In this study, the lack of deleterious effects of corticosterone on short-term memory may result from the different strength of memory for the to-be remembered information, which critically depends on the time interval elapsed between the acquisition and test trials. Moreover, the addition at the test session of the second short-term trial constitutes a shift in the behavioral procedure, which possibly engages the subject in a cognitive processing of information different from that sustaining memory retrieval performance upon the first trial. Thus, both short-term memory testing and the shift of behavioral procedure (forced choices $v s$ discrete trial) may involve different brain circuitries, which could compensate the corticosteroneinduced hippocampus dysfunction. Whatever the explanations, the high level of alternation rates observed in the short-term trial with the experimental mice show that both stress and the pharmacological treatments did not impair the ability to alternate per se. Thus, the deficit observed in the $24 \mathrm{~h}$ delayed test trial in experimental mice cannot be ascribed to an intrinsic impairment of alternation behavior.

In conclusion, our study provides strong in vivo evidence that the membrane GRs in the dHPC mediating the rapid and non-genomic effects of stress and GCs on memory retrieval are of MR but not GR type. Given the present results, we intend to investigate in a further study the functional role of the GRs of the ventral hippocampus in relation to the time-course evolution of the stress-induced corticosterone rise and associated memory retrieval impairments for short $(15 \mathrm{~min})$ and long $(60 \mathrm{~min})$ delays. Indeed, it has been shown that the dorsal and ventral hippocampus are functionally distinct structures (Fanselow and Dong, 2010), mainly as regards the density and balance of MRs and GRs and brain connectivity (Segal et al, 2010).

\section{ACKNOWLEDGEMENTS}

We thank Dr Frances Ash (ashberac@free.fr) for her language assistance. We are grateful to Dr Jean-Marie Schmitter from Universités de Bordeaux for MALDI analysis of Cort-3CMO-BSA. This research was supported by the CNRS and by a grant (Opération no. 03co01505-PEA 010801) from DGA/DET/SCET/CEP/SHP, Paris, France.

\section{DISCLOSURE}

We wish to extend the following statements: except for income received from my primary employer, no financial support or any compensation has been received from neither any individual nor corporate entity over the past 3 years for either research or professional service. Further, no single personal financial holding may exist or be perceived as constituting a potential conflict of interest.

\section{REFERENCES}

Barsegyan A, Mackenzie SM, Kurose BD, McGaugh JL, Roozendaal B (2010). Glucocorticoids in the prefrontal cortex enhance memory consolidation and impair working memory by a common neural mechanism. Proc Natl Acad Sci USA 107: 16655-16660.

Beracochea D, Jaffard R (1985). Memory deficits subsequent to chronic consumption of alcohol in mice: an analysis based on spontaneous alternation behavior. Behav Brain Res 15: $15-25$.

Borde N, Jaffard R, Beracochea DJ (1996). Effects of methyl beta-carboline-3-carboxylate on memory impairments induced by chronic alcohol consumption in mice. Prog Neuropsychopharmacol Biol Psychiatry 20: 1377-1387.

Borski RJ (2000). Nongenomic membrane actions of glucocorticoids in vertebrates. Trends Endocrinol Metab 11: 427-436.

Breuner CW, Greenberg AL, Wingfield JC (1998). Noninvasive corticosterone treatment rapidly increases activity in Gambel's white-crowned sparrows (Zonotrichia leucophrys gambelii). Gen Comp Endocrinol 111: 386-394.

Brunner R, Schaefer D, Hess K, Parzer P, Resch F, Schwab S (2006). Effect of high-dose cortisol on memory functions. Ann NY Acad Sci 1071: 434-437.

Celerier A, Pierard C, Rachbauer D, Sarrieau A, Beracochea D (2004). Contextual and serial discriminations: a new learning paradigm to assess simultaneously the effects of acute stress on retrieval of flexible or stable information in mice. Learn Mem 11: 196-204.

Chaouloff F, Groc L (2011). Temporal modulation of hippocampal excitatory transmission by corticosteroids and stress. Front Neuroendocrinol 1: 25-42.

Chauveau F, Célérier A, Ognard R, Pierard C, Béracochéa D (2005). Effects of ibotenic acid lesions of the mediodorsal thalamus on memory: relationship with emotional processes in mice. Behav Brain Res 156: 215-223.

Chauveau F, Tronche C, Piérard C, Liscia P, Drouet I, Coutan M et al. (2010). Rapid stress-induced corticosterone rise in the hippocampus reverses serial memory retrieval pattern. Hippocampus 1: 196-207.

Conboy L, Sandi C (2010). Stress at learning facilitates memory formation by regulating AMPA receptor trafficking through a glucocorticoid action. Neuropsychopharmacology 35: 674-685.

Dallman MF (2005). Fast glucocorticoid actions on brain: back to the future. Front Neuroendocrinol 26: 103-108.

de Kloet ER, Oitzl MS, Joels M (1999). Stress and cognition: are corticosteroids good or bad guys? Trends Neurosci 22: 422-426.

de Quervain DJ, Roozendaal B, McGaugh JL (1998). Stress and glucocorticoids impair retrieval of long-term spatial memory. Nature 394: 787-790.

Donley MP, Schulkin J, Rosen JB (2005). Glucocorticoid receptor antagonism in the basolateral amygdala and ventral hippocampus interferes with long-term memory of contextual fear. Behav Brain Res 164: 197-205.

Falkenstein E, Tillmann HC, Christ M, Feuring M, Wehling M (2000). Multiple actions of steroid hormones - a focus on rapid, nongenomic effects. Pharmacol Rev 52: 513-556. 
Fanselow MS, Dong HW (2010). Are the dorsal and ventral hippocampus functionally distinct structures? Neuron 65: 7-19.

Ferguson D, Sapolsky R (2007). Mineralocorticoid receptor overexpression differentially modulates specific phases of spatial and nonspatial memory. J Neurosci 27: 8046-8052.

Groc L, Choquet D, Chaouloff F (2008). The stress hormone corticosterone conditions AMPAR surface trafficking and synaptic potentiation. Nat Neurosci 8: $868-870$.

Joëls M (2008). Functional actions of corticosteroids in the hippocampus. Eur J Pharmacol 583: 312-321.

Joels M, Karst H, DeRijk R, De Kloet ER (2007). The coming out of the brain mineralocorticoid receptor. Trends Neurosci 31: 1-7.

Joels M, Pu Z, Wiegert O, Oitzl MS, Krugers HJ (2006). Learning under stress: how does it work? Trends Cogn Sci 10: 152-158.

Karst H, Berger S, Turiault M, Tronche F, Schütz G, Joëls M (2005). Mineralocorticoid receptors are indispensable for nongenomic modulation of hippocampal glutamate transmission by corticosterone. Proc Natl Acad Sci USA 102: 19204-19207.

Khaksari M, Rashidy-Pour A, Vafei AA (2007). Central mineralocorticoid receptors are indispensable for corticosteroneinduced impairment of memory retrieval. Neuroscience 149: 729-738.

Liu L, Duff K (2008). A technique for serial collection of cerebrospinal fluid from the cisterna magna in mouse. $J$ Vis Exp 10: pii: 960.

Lupien SJ, Lepage M (2001). Stress, memory, and the hippocampus: can't live with it, can't live without it. Behav Brain Res 127: 137-158.

Makara GB, Haller J (2001). Non-genomic effects of glucocorticoids in the neural system. Evidence, mechanisms and implications. Prog Neurobiol 65: 367-390.

McEwen BS, Sapolsky RM (1995). Stress and cognitive function. Curr Opin Neurobiol 5: 205-216.

McGaugh JL, Roozendaal B (2002). Role of adrenal stress hormones in forming lasting memories in the brain. Curr Opin Neurobiol 12: 205-210.

Orchinik M, Murray TF, Moore FL (1991). A corticosteroid receptor in neuronal membranes. Science 252: 1848-1851.

Paxinos G, Franklin KBJ (2001). The Mouse Brain in Stereotaxic Coordinates, 2nd edn. San Diego: Academic Press, pp 1-296.

Pfaff DW, Silva MT, Weiss JM (1971). Telemetered recording of hormone effects on hippocampal neurons. Science 172: 394-395.

Roozendaal B, Hahn EL, Nathan SV, de Quervain DJ, McGaugh JL (2004). Glucocorticoid effects on memory retrieval require

concurrent noradrenergic activity in the hippocampus and basolateral amygdala. J Neurosci 24: 8161-8169.

Roozendaal B, Phillips RG, Power AE, Brooke SM, Sapolsky RM, McGaugh JL (2001). Memory retrieval impairment induced by hippocampal CA3 lesions is blocked by adrenocortical suppression. Nat Neurosci 4: 1169-1171.

Sajadi AA, Samaei SA, Rashidy-Pour A (2006). Intra-hippocampal microinjections of anisomycin did not block glucocorticoidinduced impairment of memory retrieval in rats: an evidence for non-genomic effects of glucocorticoids. Behav Brain Res 173: $158-162$.

Sandi C, Venero C, Guaza C (1996). Novelty-related rapid locomotor effects of corticosterone in rats. Eur J Neurosci 8: 794-800.

Sapolsky RM, Romero LM, Munck AU (2000). How do glucocorticoids influence stress responses? Integrating permissive, suppressive, stimulatory, and preparative actions. Endocr Rev 21: 55-89.

Segal M, Richter-Levin G, Maggio N (2010). Stress-induced dynamic routing of hippocampal connectivity: a hypothesis. Hippocampus 12: $1332-1338$.

Stafford JM, Lattal JM (2009). Direct comparisons of the size and persistence of anisomycin-induced consolidation and reconsolidation deficits. Learn Mem 16: 494-503.

Tasker JG, Di S, Malcher-Lopes R (2006). Minireview: rapid glucocorticoid signaling via membrane-associated receptors. Endocrinology 147: 5549-5556.

Tronche C, Piérard C, Coutan M, Chauveau F, Liscia P, Béracochéa D (2010). Increased stress-induced intra-hippocampus corticosterone rise associated with memory impairments in middle-aged mice. Neurobiol Learn Mem 3: 343-351.

Venero C, Borrell J (1999). Rapid glucocorticoid effects on excitatory amino acid levels in the hippocampus: a microdialysis study in freely moving rats. Eur J Neurosci 11: 2465-2473.

Yehuda R, Harvey PD, Buchsbaum M, Tischler L, Schmeidler J (2007). Enhanced effects of cortisol administration on episodic and working memory in aging veterans with PTSD. Neuropsychopharmacology 32: 2581-2591.

(c) SOMERIEHIS RESER This work is licensed under the Creative Commons Attribution-NonCommercial-No Derivative Works 3.0 Unported License. To view a copy of this license, visit http://creativecommons.org/licenses/ by-nc-nd/3.0/ 